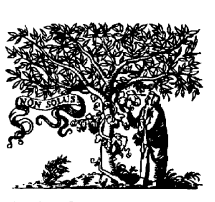

ELSEVIER

\title{
Effect of heat input on plastic deformation of undermatched welds
}

\author{
Altino J.R. Loureiro \\ Department of Mechanical Engineering, University of Coimbra, Pinhal de Marrocos, 3030 Coimbra, Portugal
}

\begin{abstract}
The aim of this work is to study the tensile properties of undermatch welds carried out in high strength quenched and tempered steel, RQT701 (British Steel). Two different heat inputs were used in order to obtain distinct mechanical properties in the weld metal (WM) and the heat-affected zone (HAZ) of the welds. Attention was focused on the microstructure and mechanical properties of the welded joints. Real stress-real strain curves of specimens sampling the WM, the WM in conjunction with the HAZ and the three zones altogether (WM, HAZ and BM) were analysed. The increase of heat input coarsened the microstructure and diminished the hardness in the WM and HAZ. A loss of hardness was also observed in the subcritical zone probably due to carbide precipitation. The increase of heat input increases the yield and tensile strength undermatching of the WM and also produces HAZ undermatching. The undermatch condition induces a concentration of plastic flow in the weakest zone and a loss of strength and ductility of the weld when loaded in tension.
\end{abstract}

(C) 2002 Elsevier Science B.V. All rights reserved.

Keywords: Undermatched welds; Plastic deformation; Strain-hardening exponent; Heat input; Quenched and tempered steel

\section{Introduction}

Welded joints are by nature heterogeneous materials, presenting a gradient of microstructures and mechanical properties (hardness, strength and toughness) through the weld metal (WM) and the heat-affected zone (HAZ). An intermixing and dilution phenomena in the WM and complex induced thermal cycles in the HAZ motivate this evolution [1,2].

The performance of the welded joint seems to depend on the size and the level of mismatching (relative strength and toughness of each zone) [3]. It is usual to classify the welds as overmatched, evenmatched or undermatched, if the yield or the ultimate strength value of the WM is, respectively, superior, equal or inferior to that of the BM.

Overmatched welds are generally used in structural components under tension loads [4], in order to guarantee the transfer of yielding to the base material, in case of plastic flow of the component. Traditionally defects occur in the WM or HAZ.

Undermatched welds are sometimes used in joining high strength steels with the aim of minimising the hydrogen induced cold cracking tendency, reducing or even preventing costly preheating operations. The temperature reduction depends on the properties of the deposited WM, in particular on the strength and toughness [5].
When soft WM is used only in root passes the strength of the weld seems not to be affected [5,6] and the installed residual stress level is lower than that of overmatched welds [5]. If the soft material is used in the whole thickness of welded joint the performance of the structural component is a function not only of the grade of mismatch but also of the weld geometry and loading mode $[7,8]$.

Undermatching values up to $25 \%$ may be tolerated in structural components, loaded in compression or shear, without affecting their performance. If defective butt welds are to be loaded in tension in a direction perpendicular to the weld axis, the grade of undermatching should not be lower than $12 \%$ [9]. The geometry of the joint and the size and orientation of the defects should not be forgotten because they affect the constraint and consequently the plastic flow capacity of the weld $[9,10]$.

Finally the strain-hardening exponent of the zone where the defect is located seems to be of vital importance to determine the capacity of this zone to harden, transferring the plastic flow to the adjacent material. This coefficient is frequently characterised in a simplified way by the yield to tensile strength ratio $[9,11]$.

With the exception of a few pieces of work [11,12], the HAZ is not taken into account in the study of the performance of the welded joint. This procedure may be motivated by the difficulty in characterising the mechanical properties of this zone, due to its heterogeneity and small size. However, most of the high strength steels and many aluminium

E-mail address: altino.loureiro@dem.uc.pt (A.J.R. Loureiro). 
alloys present a marked loss of hardness and strength in the HAZ $[13,14]$, which may negatively affect the performance of the welded joint.

Some authors $[12,15]$ have made a mechanical characterisation of the HAZ using weld-simulated specimens, nevertheless with this procedure, the effects of the gradient of microstructures and of the constraint are neglected.

The aim of this work is to study the effect of the welding procedure on the microstructure and mechanical properties of (undermatched) welds and analyse its influence on the performance under tension of the welded joint.

\section{Experimental procedure}

Welds were produced in coupon plates of a high strength quenched and tempered steel (RQT 701-British Steel), of $25 \mathrm{~mm}$ thick, using a submerged arc welding process. A K-type joint preparation was used and the weld beads were deposited alternately on one and the other side of the plates in order to minimise weld distortion. Chemical composition of the parent plates is indicated in Table 1.

Coupon plates were preheated to a temperature of $100{ }^{\circ} \mathrm{C}$ in order to prevent hydrogen induced cold cracking.
Two root beads were executed in each coupon plate, by manual metal arc, with basic electrodes AWS/SFA A5.1: E7018, before automatic welding. Submerged arc welds were performed with heat inputs of $2 \mathrm{~kJ} / \mathrm{mm}$ (reference R2) and $5 \mathrm{~kJ} / \mathrm{mm}$ (reference R5), using the couple flux/wire OK Flux 10.62/OK Autrod 13.43 (ESAB) with $4 \mathrm{~mm}$ wire diameter. Welding procedure is illustrated in Table 2. The chemical composition of the deposited WM is similar in the welds done with different heat inputs and it is indicated in Table 1.

Welds were performed transversely to the rolling direction. Thermal cycles in the HAZ were recorded using K-type thermocouples with $0.25 \mathrm{~mm}$ diameter, welded in the coupon plates.

Specimens used in the characterisation of the microstructure, hardness and tensile properties were extracted in a direction transverse to the welds. Vickers hardness indentations were made, using a $1 \mathrm{~kg}$ load, along a line parallel to the plate surface and situated $6 \mathrm{~mm}$ beneath this surface. Tensile specimens sampling the WM, the WM and HAZ together (WM + HAZ) and these zones and the base material $(\mathrm{WM}+\mathrm{HAZ}+\mathrm{BM})$ were extracted according the scheme indicated in Fig. 1.

The tensile tests were carried out at room temperature in a $100 \mathrm{kN}$ capacity servo hydraulic testing machine, using a testing speed of $0.45 \mathrm{~mm} / \mathrm{min}$. Cylindrical tensile specimens of $8 \mathrm{~mm}$ in diameter and $12.5 \mathrm{~mm}$ gauge length for zones $\mathrm{W}$ and WH and $50 \mathrm{~mm}$ for zones WHB and for those extracted

Table 1

Chemical composition of the parent plate and of the deposited WMs

\begin{tabular}{|c|c|c|c|c|c|c|c|c|c|c|c|}
\hline$\% \mathrm{C}$ & $\% \mathrm{Si}$ & $\% \mathrm{Mn}$ & $\% \mathrm{P}$ & $\% \mathrm{~S}$ & $\% \mathrm{Cr}$ & $\% \mathrm{Mo}$ & $\% \mathrm{Ni}$ & $\% \mathrm{Cu}$ & $\% \mathrm{Ti}$ & $\% \mathrm{~V}$ & $\% \mathrm{Al}$ \\
\hline \multicolumn{12}{|c|}{ Parent plate } \\
\hline 0.17 & 0.349 & 1.207 & 0.019 & 0.013 & 0.147 & 0.136 & 0.242 & 0.136 & 0.027 & 0.008 & 0.011 \\
\hline \multicolumn{12}{|l|}{$W M$} \\
\hline 0.04 & 0.14 & 1.295 & 0.03 & 0.026 & 0.593 & 0.476 & 0.828 & 0.091 & 0.006 & 0.016 & 0.028 \\
\hline
\end{tabular}

Table 2

Welding procedure and welding data used to produce the welds

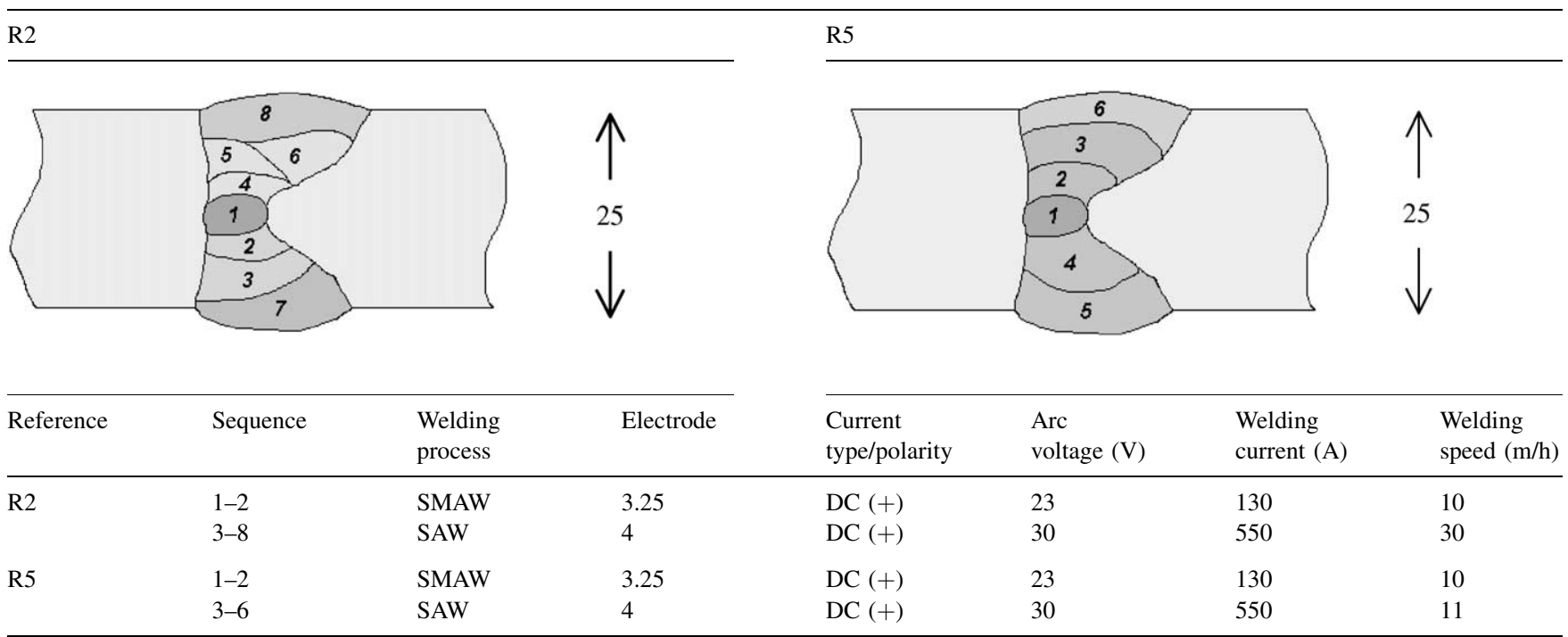



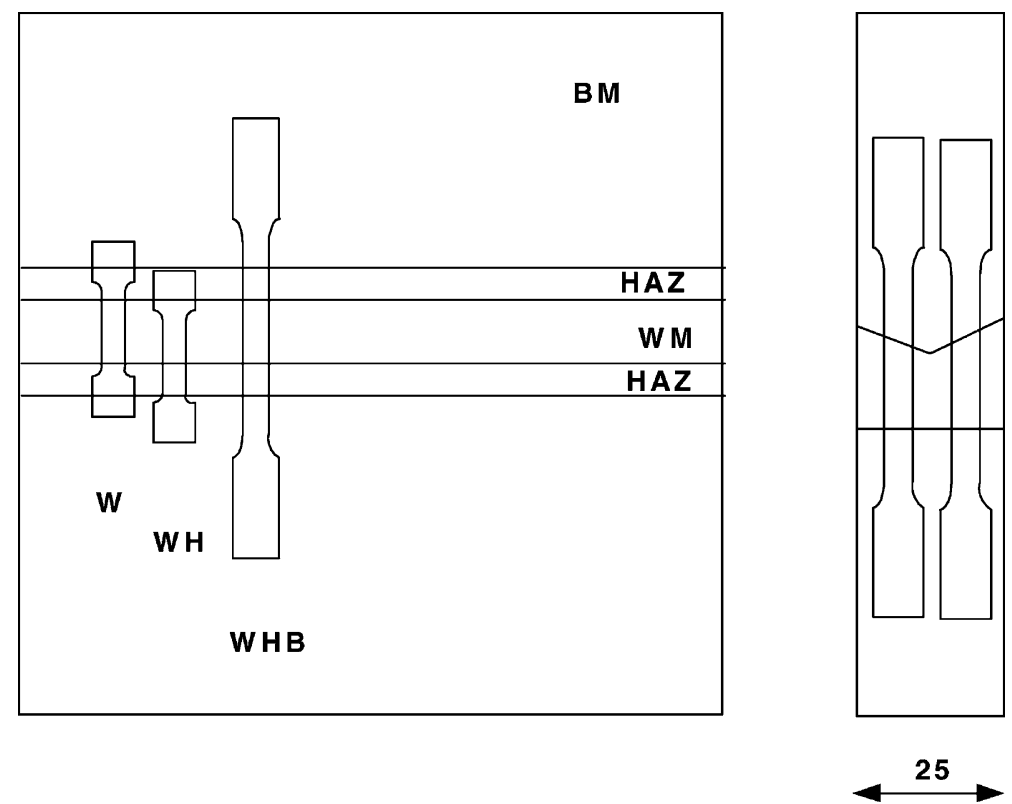

Fig. 1. Mode of extraction of tensile specimens. W—specimens sampling WM; WH—specimens sampling WM and HAZ; WHB—specimens sampling WM, HAZ and BM together.

from the base material (BM), were used. Real stress-real strain curves were obtained from the nominal ones, in the zone of homogeneous plastic deformation, using the following equations:

$$
\begin{aligned}
& \varepsilon=\ln (1+e) \\
& \sigma_{\mathrm{r}}=\sigma_{\mathrm{c}}(1+e)
\end{aligned}
$$

where $\varepsilon$ is the real strain, $e$ the nominal strain, $\sigma_{\mathrm{r}}$ the real stress, and $\sigma_{\mathrm{c}}$ the nominal stress. The work hardening exponent of each zone of the welds was determined assuming that the plastic behaviour may be described by the Ludwick law $\left(\sigma_{\mathrm{r}}=K \varepsilon^{\mathrm{n}}\right)$. Plotting the log strain-log stress curve, the work hardening exponent is given by the slope of the straight line.

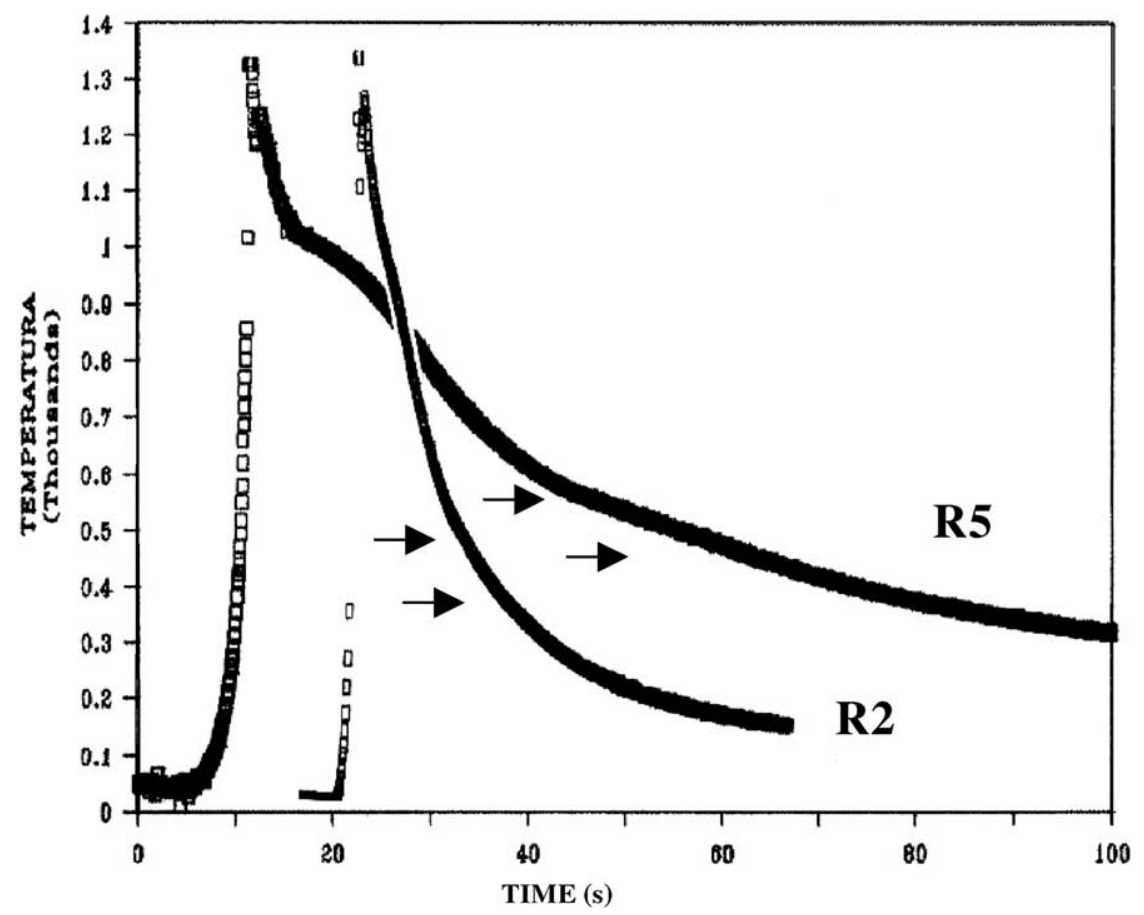

Fig. 2. Thermal cycles measured in the CGHAZ of the welds. R2 - weld carried out with $2 \mathrm{~kJ} / \mathrm{mm}$ and R5-weld produced with $5 \mathrm{~kJ} / \mathrm{mm}$. 


\section{Results and discussion}

\subsection{Thermal cycles}

Two examples of thermal cycle curves obtained in the coarse grain heat-affected zone (CGHAZ) of the welds are shown in Fig. 2. The peak temperature in each case is $1350{ }^{\circ} \mathrm{C}$ and the cooling time between 800 and $500{ }^{\circ} \mathrm{C}$ $\left(\Delta t_{8 / 5}\right)$ is 6 and $28 \mathrm{~s}$, for welds carried out, respectively, with 2 and $5 \mathrm{~kJ} / \mathrm{mm}$. A significant decrease in the cooling rate is observed with the increase of heat input as well as a growth of the time above $1000{ }^{\circ} \mathrm{C}$, that passes from 3 to $8 \mathrm{~s}$.

Temperatures at the start and finish of the phase transformation are apparent in Fig. 2, in the thermal cycle of a weld carried out with $5 \mathrm{~kJ} / \mathrm{mm}$ heat input. The temperatures of start $\left(T_{\mathrm{s}}\right)$ and finish $\left(T_{\mathrm{f}}\right)$, obtained by a numeric derivation of the thermal cycles, are $T_{\mathrm{s}}=490{ }^{\circ} \mathrm{C}$ and $T_{\mathrm{f}}=385$ for welds R2 and $T_{\mathrm{s}}=560{ }^{\circ} \mathrm{C}$ and $T_{\mathrm{f}}=450{ }^{\circ} \mathrm{C}$ for welds R5. The aim of the derivative curves is to emphasise the discontinuities or changes in the slope, revealing phase transformations. The increase of heat input increases the phase transformation temperatures, suggesting changes in the microstructures obtained in each case.

\subsection{Microstructures}

Fig. 3 shows the microstructure of the deposited WM of the welds R2 and R5. The microstructure is composed mainly of acicular ferrite, with some islands of primary ferrite. A slight coarsening of the microstructure with the increase of heat input may be observed in the micrographs.

(a)

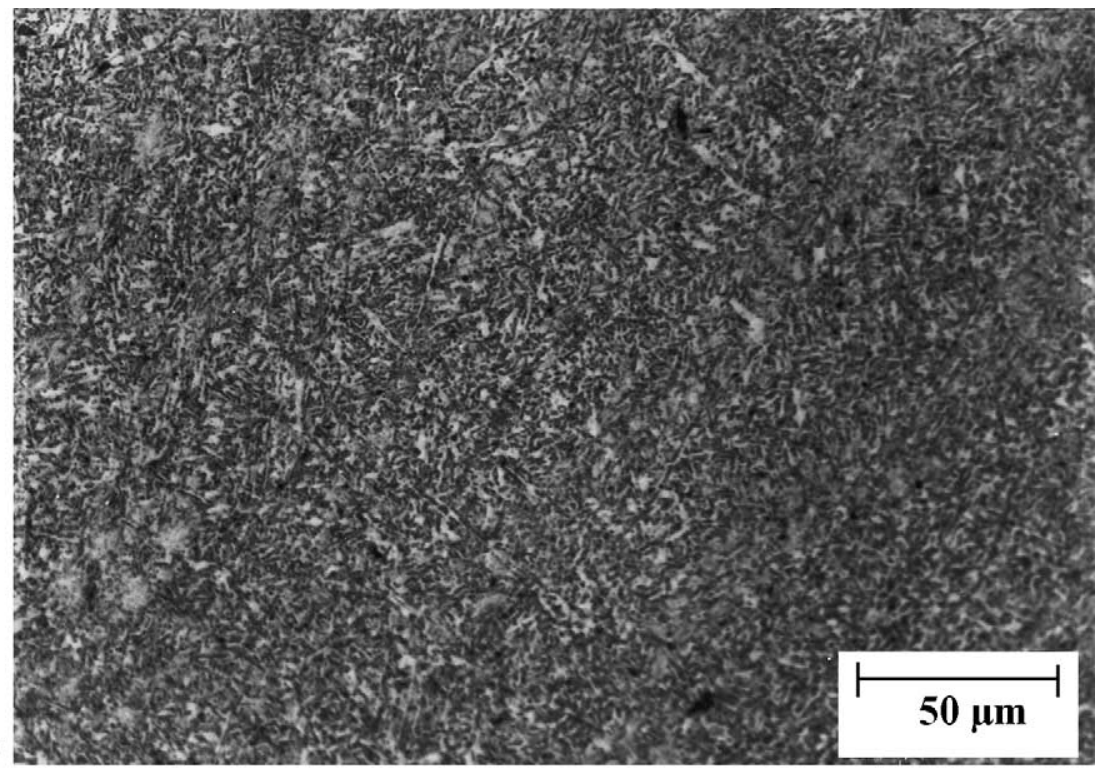

(b)

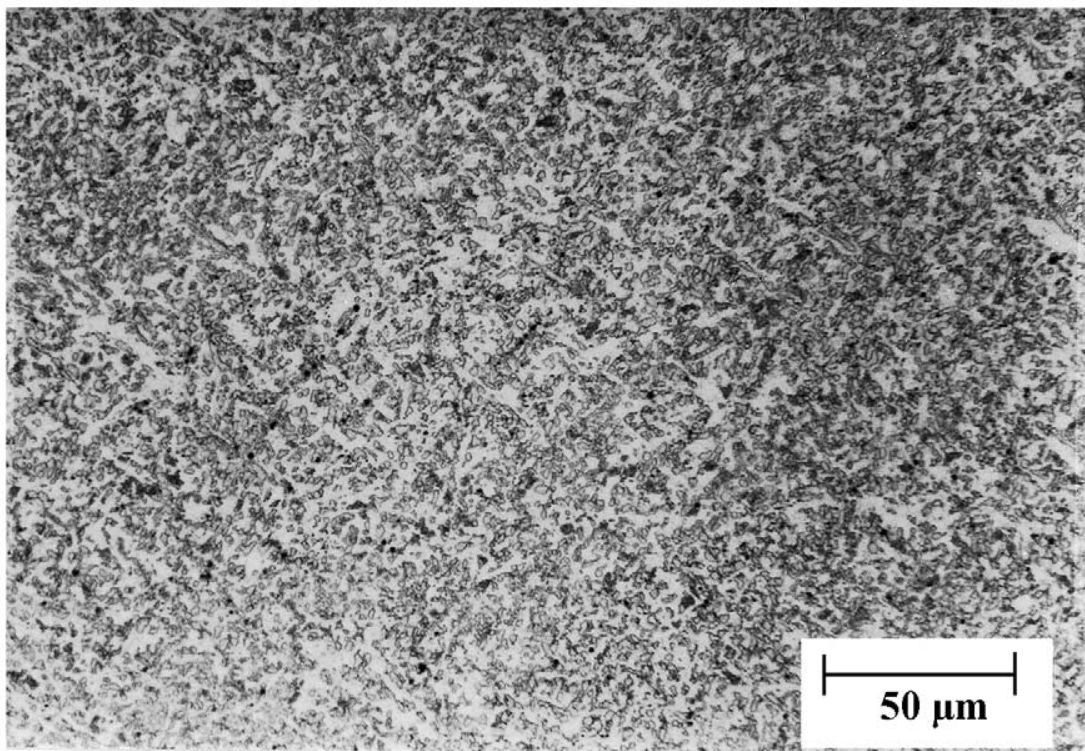

Fig. 3. Microstructures of the WM of the welds carried out with (a) 2 and (b) $5 \mathrm{~kJ} / \mathrm{mm}$. 
(a)

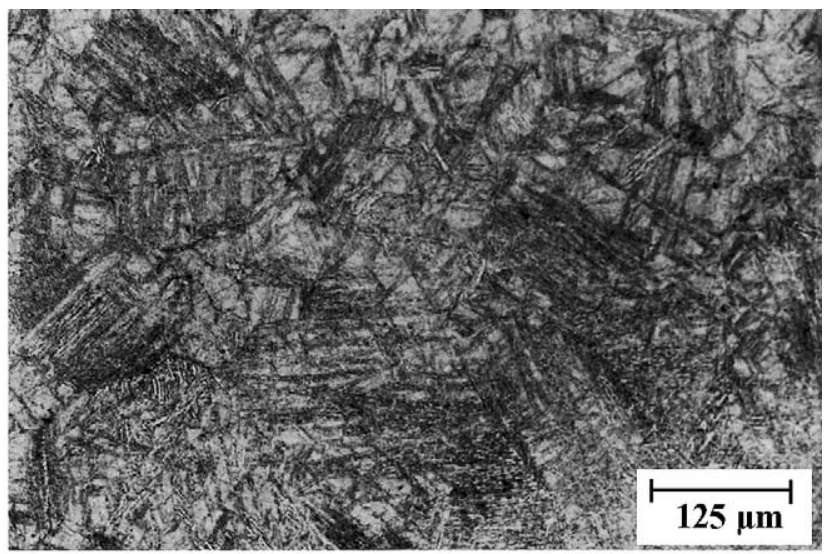

(b)

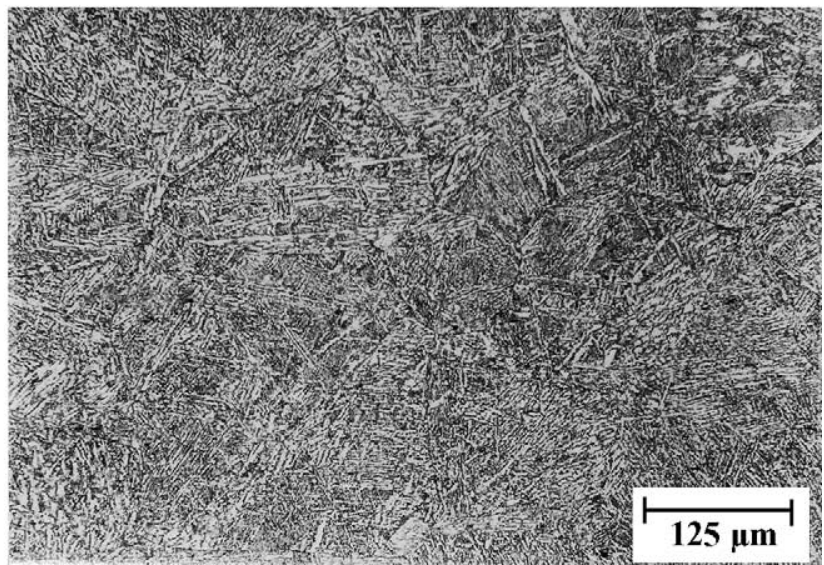

Fig. 4. Microstructure of the CGHAZ of welds carried out with (a) 2 and (b) $5 \mathrm{~kJ} / \mathrm{mm}$.

Fig. 4(a) and (b) illustrates the microstructures observed in the CGHAZ of the welds, near the fusion line. The prior austenite grain size ( $\gamma$ g.s.) in this zone shows a substantial growth with the increase of heat input. Measuring the $\gamma$ g.s. following a line parallel to the fusion line situated at a distance of $50 \mu \mathrm{m}$, the values of $36 \pm 4$ and $83 \pm 6 \mu \mathrm{m}$ were obtained, respectively, for welds performed with 2 and $5 \mathrm{~kJ} /$ $\mathrm{mm}$. The grain size of the parent plate is $12.5 \pm 2 \mu \mathrm{m}$. The interception method (Heyn) was used in the evaluation.

Significant modifications may be observed in the microstructure with the increase of heat input. In morphological terms the microstructure in the HAZ of the weld R2 is not

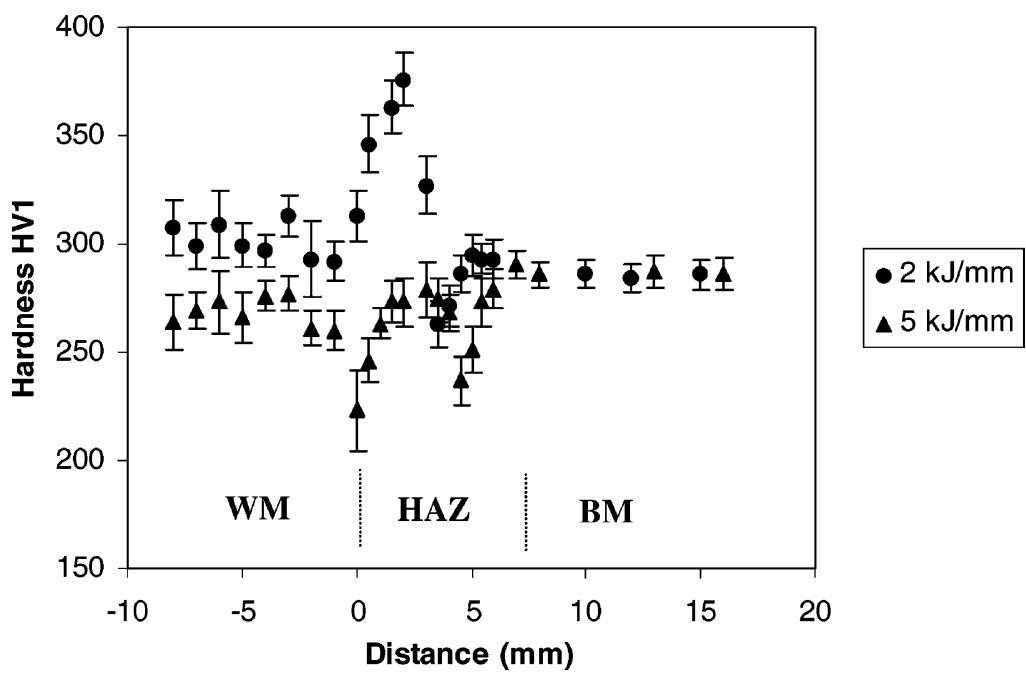

Fig. 5. Vickers hardness measured in a cross-section of the welds, in a direction transverse to the weld beads, 5 mm beneath the plate surface. WM-weld metal; HAZ-heat-affected zone; BM-base metal. Bars indicate the $95 \%$ confidence limits for the mean. 


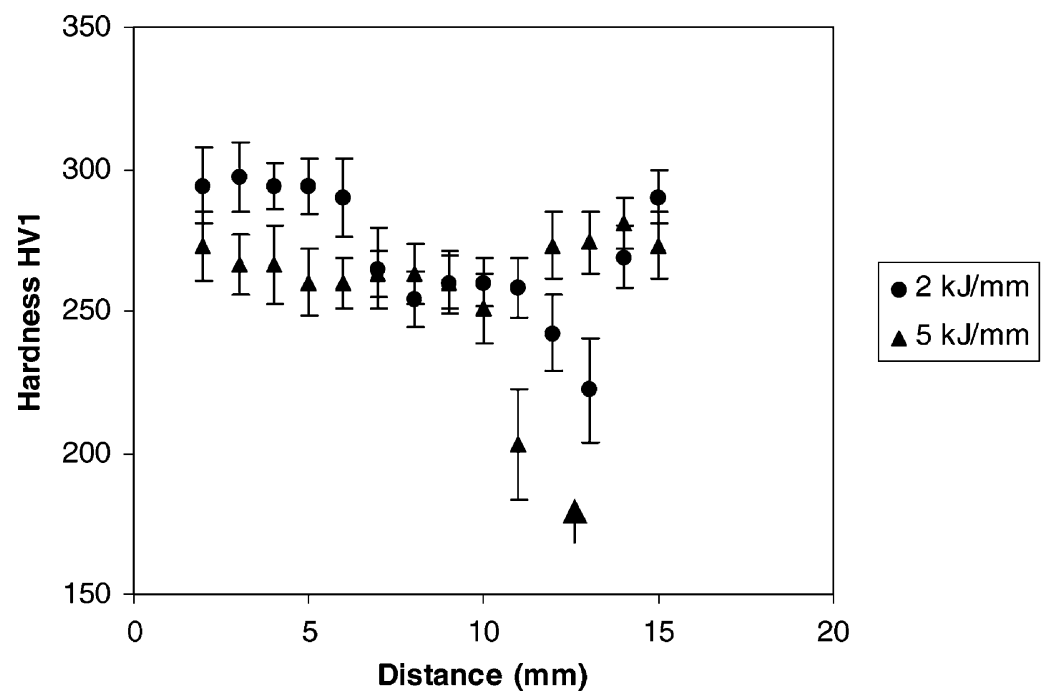

Fig. 6. Vickers hardness measured in the WM, through the thickness. Half thickness-4. Bars indicate the $95 \%$ confidence limits for the mean.

easily discernible under optical microscope, but seems to be composed mainly of lower bainite and tempered martensite. The increase of heat input and consequently of the time above $1000{ }^{\circ} \mathrm{C}$ and of the cooling time, promotes the formation and coarsening of upper bainite and even the appearance of some ferrite side plates, as shown in Fig. 4(b).

\subsection{Hardness}

Figs. 5 and 6 illustrate the evolution of the hardness in the cross-section of the welds, respectively, in a direction transverse to the welds and in the WM, through the thickness.

The increase of heat input induces a marked decrease of hardness in the WM and HAZ of the welds. This reduction may be associated to the changes in the microstructures, observed in these zones. In the WM this behaviour may be due to the increase of the volume fraction of ferrite and the coarsening of the microstructure. In Fig. 6 it is also possible to observe a reduction of hardness in thickness, in the case of weld R2, due to the annealing effect of subsequent weld beads. The drastic reduction of hardness at half thickness, observed in the two types of welds, is due to the presence of the WM deposited with basic electrodes, using a manual metal arc process.

Maximum values of hardness in the CGHAZ confirm the suspicion of the existence of lower bainite and tempered martensite in this zone, in the case of welds produced with $2 \mathrm{~kJ} / \mathrm{mm}$ heat input. In fact, according to Yurioka et al. [16] the maximum hardness of this HAZ should be $444 \mathrm{HV} 10$, if the structure was totally martensitic, and $223 \mathrm{HV} 10$, in the case of a non-martensitic microstructure. Mixed microstructures shall remain at this interval of hardness.

The reduction of hardness in the HAZ of welds produced with $5 \mathrm{~kJ} / \mathrm{mm}$ is due to the formation and coarsening of the upper bainite. A significant loss of hardness may be observed in both types of welds at a distance of approximately $5 \mathrm{~mm}$ from the fusion boundary. The decrease of hardness is of $40 \mathrm{HV} 1$ in welds carried out with $5 \mathrm{~kJ} / \mathrm{mm}$. This loss occurs in the subcritical HAZ and may be motivated by tempering of the martensite. This behaviour is usual in quenched and tempered steel [17].

\subsection{Tensile properties}

The base material presents a stress-strain curve with a well-defined yield point elongation (yield plateau) and a small strain-hardening exponent, as illustrated in Fig. 7 and Table 3, typical of some high strength steels. The yield plateau attains an average conventional strain of $2.7 \%$.

Tensile tests of the welds revealed that plastic deformation occurs preferentially in WM, for specimens $\mathrm{R} 2$, and in the HAZ, for specimens R5. This is illustrated in Fig. 8. Specimens were extracted in order to exclude material of the root zone, as indicated in Fig. 1, however even if root material is sampled, the fracture of R5 specimens continues to be in the HAZ, as is intentionally shown in Fig. 8. This behaviour is

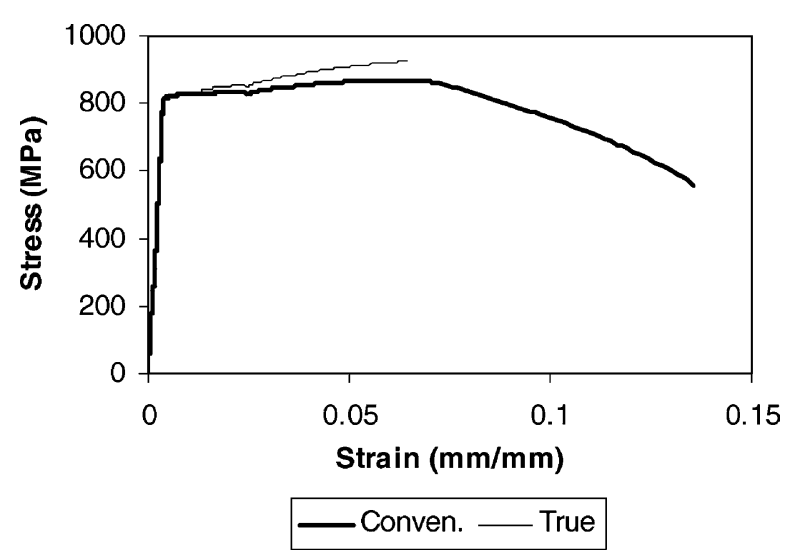

Fig. 7. Conventional and true strain-true stress curves of the base material. 
Table 3

Tensile test data of specimens sampling the WM, WM and HAZ (WH) and the three zones together (WHB) ${ }^{\mathrm{a}}$

\begin{tabular}{|c|c|c|c|c|c|c|c|c|}
\hline Material/weld & Zones sampled & $R_{\mathrm{e}}(\mathrm{MPa})$ & $R_{\mathrm{m}}(\mathrm{MPa})$ & $e_{\mathrm{m}}(\%)$ & $n 1(2 \%)$ & $n 2(2-4 \%)$ & $n$ & Fracture \\
\hline Base material & $\mathrm{BM}$ & $819(2.4)$ & $868(1.3)$ & $6.2(0.65)$ & 0.03 & 0.09 & $0.09(0.004)$ & $\mathrm{BM}$ \\
\hline \multirow[t]{3}{*}{$\mathrm{R} 2$} & WM & $668(8.3)$ & $803(11.1)$ & $8.3(0.23)$ & 0.075 & 0.11 & $0.094(0.009)$ & WM \\
\hline & WH & $673(9.7)$ & $776(8)$ & $5.7(0.3)$ & 0.096 & 0.084 & $0.098(0.013)$ & WM \\
\hline & WHB & 681 (12.9) & $776(6.7)$ & $2.8(0.13)$ & 0.09 & - & $0.098(0.012)$ & WM \\
\hline \multirow[t]{3}{*}{ R5 } & WM & $627(9.7)$ & $738(10.8)$ & $8.6(0.43)$ & 0.12 & 0.123 & $0.125(0.008)$ & WM \\
\hline & WH & $558(15.7)$ & $661(11.4)$ & $9.7(0.69)$ & 0.118 & 0.135 & $0.127(0.004)$ & HAZ \\
\hline & WHB & $578(15.3)$ & $672(13.5)$ & $3.3(0.36)$ & 0.135 & - & $0.132(0.009)$ & $\mathrm{HAZ}$ \\
\hline
\end{tabular}

${ }^{\mathrm{a}} R_{\mathrm{e}}$-nominal yield stress $(0.2 \%) ; R_{\mathrm{m}}$-nominal tensile strength; $e_{\mathrm{m}}$-nominal strain at maximum load; $n 1$-strain-hardening exponent for $2 \%$ plastic deformation; $n 2$ - strain-hardening exponent for plastic deformation between 2 and $4 \%$; $n$-strain-hardening exponent for the plastic deformation up to the maximum load point. The sample standard deviation is indicated between round brackets.

probably due to the orientation and small width of the soft zone. Welded specimens do not show any yield plateau, as shown in Fig. 9. The results of the tensile tests are summarised in Table 3. Nominal stress and nominal strain values are indicated and each value represents an average of five

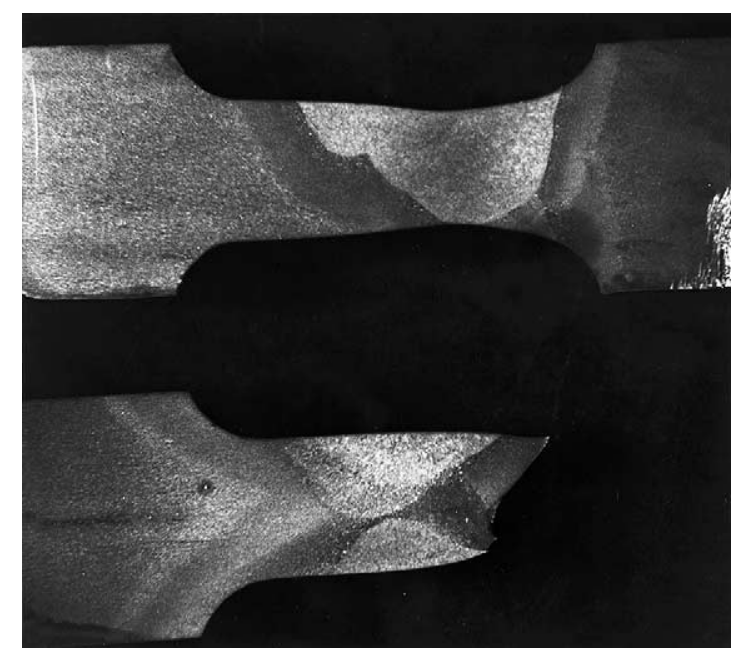

Fig. 8. Macrograph of two tensile specimens: the first extracted from a R2 weld and the second from the central zone of a R5 weld.

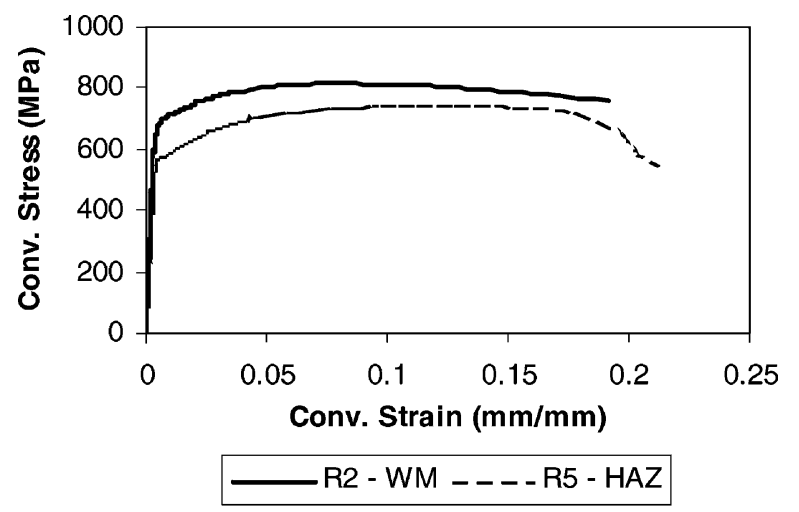

Fig. 9. Conventional stress-strain curves of the WM of R2 and HAZ of R5. specimens. The hardening exponents are determined from the true stress-true strain curves.

In both the cases studied, a WM undermatching condition is obtained. The grade of undermatching increases with the increase of heat input, as shown in Table 4. The grade of yield strength undermatching is above $12 \%$ for both welds, which accordingly [9], should provoke a concentration of plastic flow in the weakest zone and a loss of strength and ductility. This behaviour may be observed in Table 3 .

The analysis of this table shows that the nominal strain at maximum load of specimens sampling the three zones, specimens WHB, is lower than that of the specimens $\mathrm{WM}$ and $\mathrm{WH}$. This is due to the concentration of plastic flow in a specific zone (WM for specimens R2 and HAZ for specimens R5). In this case the clip gauge samples the three zones but only the WM or the HAZ contribute to the extension that is divided by the reference gauge length $(50 \mathrm{~mm})$.

Welds carried out at $5 \mathrm{~kJ} / \mathrm{mm}$ heat input also show a HAZ yield and tensile strength undermatching. The grade of HAZ mismatching was not determined in specimens R2 because plastic flow happened mainly in the WM. In fact the determination of the HAZ mismatch is a complex task due to the heterogeneity of this zone. In some cases their mechanical properties (yield or tensile strength) are estimated by using hardness test results [15] in order to surpass this problem and define a mismatch factor [6]. The grade of mismatch based on hardness measurements is indicated in Table 5. The average WM hardness and the minimum HAZ hardness are used to define the mismatch factor. The mismatch factors determined in the two ways are quite different, which suggests that the hardness test method should not be used to define the mismatch factor in this case.

Tension testing of specimens transverse to the weld axis, sampling the three zones of the weld, is useful to characterise the plastic capacity of the welded joint. However, it should not be used to determine the plastic capacity of the weakest zone, unless the real length of the zone under flow is considered.

If only the effective size of the zone undergoing plastic flow is concerned, the strain obtained in specimen sampling 
Table 4

Grade of mismatching obtained in welds R2 and R5 ${ }^{\mathrm{a}}$

\begin{tabular}{|c|c|c|c|c|}
\hline \multirow[t]{2}{*}{ Mismatching grade } & \multicolumn{2}{|l|}{ Mys } & \multicolumn{2}{|l|}{ Mts } \\
\hline & $\mathrm{WM} / \mathrm{BM}$ & $\mathrm{HAZ/BM}$ & $\mathrm{WM} / \mathrm{BM}$ & $\mathrm{HAZ/BM}$ \\
\hline $\mathrm{R} 2$ & $668 / 819=0.815$ & - & $803 / 868=0.925$ & - \\
\hline R5 & $627 / 819=0.765$ & $558 / 819=0.68$ & $738 / 868=0.85$ & $661 / 868=0.76$ \\
\hline
\end{tabular}

${ }^{\mathrm{a}}$ Mys_-yield strength mismatching; Mts—-tensile strength mismatching; WM-weld metal; HAZ—heat-affected zone; BM-base metal.

Table 5

Comparison between mismatch factors determined using tensile and hardness tests ${ }^{\mathrm{a}}$

\begin{tabular}{|c|c|c|c|c|}
\hline \multirow[t]{2}{*}{ Mismatching grade } & \multicolumn{2}{|l|}{ Mys (tensile tests) } & \multicolumn{2}{|c|}{ Mys (hardness tests) } \\
\hline & $\mathrm{WM} / \mathrm{BM}$ & $\mathrm{HAZ/BM}$ & WM/BM & $\mathrm{HAZ/BM}$ \\
\hline $\mathrm{R} 2$ & $668 / 819=0.815$ & - & $295 / 290=1$ & $263 / 290=0.9$ \\
\hline R5 & $627 / 819=0.765$ & $558 / 819=0.68$ & $265 / 290=0.91$ & $230 / 290=0.79$ \\
\hline
\end{tabular}

${ }^{\text {a }}$ Mys—yield strength mismatching; WM-weld metal; HAZ—heat-affected zone; BM-base metal.

in the three zones is similar to that obtained in specimen testing in one zone individually, as shown in Table 6. Results of Table 6 were obtained assuming that the average width of the WM in specimens R2 is $13 \mathrm{~mm}$ and the average HAZ width (aggregate of the two HAZs with an average width of $7 \mathrm{~mm}$ ) is $14 \mathrm{~mm}$ in specimens $\mathrm{R} 5$.

Even in this case some difference is observed between the values of strain at maximum load obtained in the specimen sampling the zone undergoing plastic flow, and the specimens sampling the three zones (R2: $8.3 \neq 9.9$ and for R5: $9.7 \neq 11.6$ ). This difference may be due to some additional plastic flow of the HAZ for R2 or WM for R5 or to variability of the size of the zone concerned. It is useful to say that the strain at maximum load is also very sensitive to the maximum load value selected. In fact a small change in the maximum load value induces a very large variation of the strain.

In any case, the plastic capacity of the WM of specimens $\mathrm{R} 2$ seems to be slightly lower than that of the HAZ of specimens R5. It is relevant to note that plastic flow depends not only on the material's own properties but also of the grade of constraint to which the material is submitted. In this case the level of constraint in the HAZ is higher than in the WM, because the width of the first zone is smaller than that of the WM. This means that the inherent plastic capacity of the HAZ of specimens R5 may be superior to that indicated in Table 6.

Where the strain-hardening exponent is concerned, three different values are presented in Table 3, because the slope of the true stress-true strain curve is usually different at the beginning and at the end of the homogeneous plastic range. The coefficient $n 1$ is determined in the plastic branch of the true stress-strain curve up to a strain of $2 \%$. The coefficient $n 2$ is defined in the interval $2-4 \%$, and $n$ is the same coefficient, evaluated between the yield point and the maximum load point.

An increase of the exponent is generally observed at the end of the homogeneous flow range, see Table 3, contradicting [11]. It is convenient to point out that these coefficients are very sensitive to the points used in the calculation.

Since the strain-hardening exponent influences the plastic flow strongly and fracture of defective structures it is important to define which strain-hardening exponent to use, for example, in the assessment of these structures. The strain-hardening rate $(n)$, evaluated between the yield point and the maximum load point is frequently used [18], assuming that the stress-strain curve of the material is a power law.

It was expected that the strain-hardening exponent, obtained from specimens that suffer plastic flow in the same

Table 6

Mechanical properties of the zones undergoing plastic flow

\begin{tabular}{lllll}
\hline Welds & Zones sampled & $l_{\mathrm{o}}$ (reference length) & $e_{\mathrm{m}}(\%)$ (strain at max load) & $n$ (strain hard. expon.) \\
\hline R2 & WM & 12.5 & 8.3 & 0.094 \\
& WHB & 50 & 2.8 & 0.098 \\
& WHB & 13 & 9.9 & 0.122 \\
R5 & WH & 12.5 & 9.7 & 0.127 \\
& WHB & 50 & 3.3 & 0.132 \\
& WHB & 14 & 11.6 & 0.156 \\
\hline
\end{tabular}




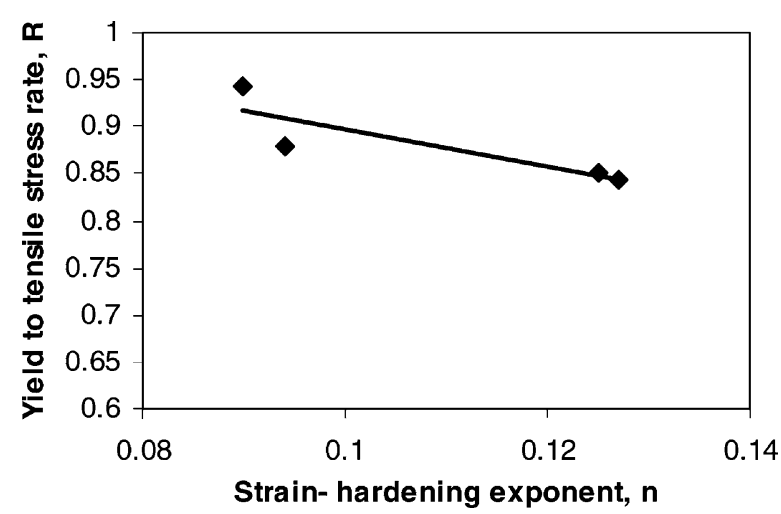

Fig. 10. Relationship between the strain-hardening exponent and the yield-tensile stress ratio.

zone of the weld, would be very similar. Table 3 shows that there is only a slight difference between the $n$ value obtained in a specimen sampling the zone under plastic flow and that of the specimen sampling the zones of the weld altogether (for $\mathrm{R} 2-n_{\mathrm{WM}}=0.094$ and $n_{\mathrm{WHB}}=0.98$; for $\mathrm{R} 5-$ $n_{\mathrm{WH}}=0.127$ and $n_{\mathrm{WHB}}=0.132$ ). According to these results the $n$ value obtained in tension tests, perpendicular to the axis of the weld may be used to characterise the weakest material of undermatched welds. The values of $n$ determined in WHB specimens assuming the effective size of the zone flow, see Table 6, are greater than those in Table 3 and seem to not corresponding to reality.

In the search for simplicity, some authors use the yield to tensile ratio $(R)$ instead of the strain-hardening exponent $[9,11]$ in the qualitative study of the performance of the welded joint. They claim that this approximation is justifiable because there is a relationship between the strainhardening rate and the yield point strength. In this case, a relationship may be established between these two parameters using the results from Table 3, as shown in Fig. 10, although the number of results is small. The curve of Fig. 10 should intercept the $Y$-axis at point $(0,1)$ in the case of the stress-strain curve being a power law. In fact if $n=0$ an elastic-perfectly plastic material is involved and $R=1$.

The strain-hardening exponent $n$ of specimens R5 is higher than that of specimens R2 suggesting larger plastic capacity of the HAZ of R5 than the WM of R2. According to Dexter [9] much larger undermatching may be tolerated if the material suffering plastic flow has a high strain-hardening rate. This is due to the hardening of the material, and the spread of plastic flow to the adjacent one. In welds R5 the weakest material is the HAZ, which has an $n$ of approximately 0.13 , that is enough to allow the transfer of part of the plastic deformation to the WM. The tensile strength of the $\mathrm{HAZ}$ is higher than the yield strength of the adjacent WM (see Table 3). However, it is possible to see from the same table that the hardening effect is not enough to achieve the full strength of the parent plate. This means that in the case of defects located in the HAZ the weld joint is not protected against catastrophic fractures. Welds R2 are also in danger due to WM undermatch.

\section{Conclusions}

The primary objective of this research was to study the effect of the heat input on the microstructure, mechanical properties and performance under tension loading of welded joints. The following conclusions may be drawn from the results presented above:

- The increase of heat input in the welding process produces a coarsening of the microstructure of the WM and mainly of the HAZ and promotes the formation and coarsening of upper bainite in this zone and even the appearance of some ferrite side plates.

- A loss of hardness was also observed in the subcritical zone probably due to carbide precipitation.

- The increase of the heat input increases the yield and tensile strength undermatching of the WM, and also produces HAZ undermatching.

- The WM yield strength undermatching levels induce a concentration of plastic flow in the weakest zone and a loss of strength and ductility of the weld when loaded in tension.

- The hardness tests method should not be used to define the mismatch factor of the several zones of the weld.

- The use of the yield to tensile ratio $(R)$, instead of the strainhardening exponent, in the qualitative study of the performance of the welded joint may be acceptable in this case.

\section{References}

[1] M.A. Quintana, M.Q. Johnson, The effects of intermixed weld metal on mechanical properties, Weld. J. 78 (3) (1999) 87s-99s.

[2] A.J.R. Loureiro, A.A. Fernandes, Toughness of CG HAZs of welds in Q and T steels, Weld. J. 73 (11) (1994) 225s-232s.

[3] M. Toyoda, C. Thaulow, J.G. Blauel, Strength mismatching and its influence on the performance of welded structures, Mismatching of Welds, ESIS 17, Mec. Eng. Publ., London, 1994, pp. 335-350.

[4] ANSI/AWS D1.1, Structural Welding Code-Steel, American Welding Society, 1995.

[5] A. Umekuni, K. Masubuchi, Usefulness of undermatched welds for high-strength steels, Weld. J. 76 (7) (1997) 256s-263s.

[6] I. Rak, M. Koçak, V. Gliha, N. Gubeljak, Fracture behaviour of overmatched high strength steel welds containing soft root layers, in: K.H. Schwalbe, M. Koçak (Eds.), Mismatching of Interfaces and Welds, GKSS Research Center Publications, 1997, pp. 627-641.

[7] F.M. Burdekin, M. Koçak, K.H. Schwalbe, R. Denys, Significance of strength mismatch in welds-summary of a round table discussion, Mismatching of Welds, ESIS 17, Mec. Eng. Publ., London, 1994, pp. 103-111.

[8] Ph. Gilles, Ch. Franco, A new J-estimation scheme for cracks in mismatching welds-the ARAMIS method, Mismatching of Welds, ESIS 17, Mec. Eng. Publ., London, 1994, pp. 661-683.

[9] R.J. Dexter, Significance of strength undermatching of welds in structural behaviour, in: K.H. Schwalbe, M. Koçak (Eds.), Mismatching of Interfaces and Welds, GKSS Research Center Publications, 1997, pp. 55-73. 
[10] M. Kirk, A. Baker, Constraint Effects in Fracture Theory and Applications, Vol. 2, ASTM STP 1244, 1995.

[11] R.M. Denys, A study of the effect of yield point elongation and strain hardening rate on the fracture behaviour of (welded) low carbon steels, in: Proceedings of the Seventh International Conference on Offshore Mechanics and Arctic Engineering, Houston, TX, 1988, pp. 405-413.

[12] R.M. Denys, A. Dhooge, Mechanical tensile properties of weld simulated HAZ microstructures in normalized, quenched-tempered and TMCP low carbon manganese steels, in: Proceedings of the Seventh International Conference on Offshore Mechanics and Arctic Engineering, Houston, TX, 1988, pp. 207-218.

[13] J. Defourny, Soudabilité des aciers produits par laminage thermomecanique ou par refroidissement acceleré, Soud. Et Techniques connexes, Juillet/Août 1994, pp. 17-35 (in French).
[14] G.O. Rading, M. Shamsuzzoha, J.T. Berry, A model of HAZ hardness profiles in $\mathrm{Al}-\mathrm{Li}-\mathrm{X}$ alloys: application to the $\mathrm{Al}-\mathrm{Li}-\mathrm{Cu}$ alloy 2095, Weld. J. 77 (10) (1998) 411s-416s.

[15] O.M. Akselsen, G. Rorvik, M.I. Onsoien, O. Grong, Assessment and predictions of HAZ tensile properties of high-strength steels, Weld. J. 68 (9) (1989) 356s-362s.

[16] N. Yurioka, M. Okumura, T. Kasuya, H.J.U. Cotton, Prediction of hardness of transformable steels, Metal Construction, April 1987, pp. 217R-223R.

[17] R. Rauch, H. Schutz, Advantages of TM-steels in welding fabrication, IIW Doc IX-1647-91.

[18] K.H. Schwalbe, A. Cornec, The engineering treatment model (ETM) and its practical application, Fatigue Fract. Mater. Struct. 14 (4) (1991) 405-412. 